\title{
Serotype-Specific Pneumococcal Status prior to PCV 13 Administration in Children and Adolescents with Inflammatory Bowel Disease
}

\author{
ALEKSANDRA BANASZKIEWICZ1, BRYGIDA TARGOŃSKA², KINGA KOWALSKA-DUPLAGA², \\ KATARZYNA KAROLEWSKA-BOCHENEK ${ }^{1}$, AGNIESZKA SIECZKOWSKA ${ }^{4}$, AGNIESZKA GAWROŃSKA ${ }^{1}$, \\ URSZULA GRZYBOWSKA-CHLEBOWCZYK ${ }^{5}$, ELŻBIETA KRZESIEK ${ }^{6}$, IZABELLA ŁAZOWSKA-PRZEOREK ${ }^{1}$, \\ MARIA KOTOWSKA ${ }^{1}$, EDYTA SIENKIEWICZ ${ }^{1}$, JAROSŁAW WALKOWIAK ${ }^{2}$, HANNA GREGOREK ${ }^{7}$ \\ ANDRZEJ RADZIKOWSKI ${ }^{1}$ and PIOTR ALBRECHT ${ }^{1}$
}

\author{
${ }^{1}$ Department of Pediatric Gastroenterology and Nutrition, Medical University of Warsaw, Warsaw, Poland \\ ${ }^{2}$ Department of Pediatric Gastroenterology and Metabolic Diseases, Poznan University of Medical Sciences \\ Poznan, Poland \\ ${ }^{3}$ Department of Pediatrics, Gastroenterology and Nutrition, Polish-American Children's Hospital \\ Jagiellonian University Medical College, Cracow, Poland \\ ${ }^{4}$ Department of Pediatric Gastroenterology, Hepatology and Nutrition, Medical University of Gdansk, Gdansk, Poland \\ ${ }^{5}$ Department of Pediatrics, Medical University of Silesia, Katowice, Poland \\ ${ }^{6}$ Department of Pediatrics, Gastroenterology and Nutrition, Wroclaw Medical University, Wroclaw, Poland \\ ${ }^{7}$ Department of Microbiology and Clinical Immunology, The Children's Memorial Health Institute, Warsaw, Poland
}

Submitted 16 May 2015, revised 16 June 2015, accepted 1 September 2015

Abstract

The aim of this study was to evaluate the serotype-specific pneumococcal status of children and adolescents with inflammatory bowel disease (IBD) who were naïve to pneumococcal vaccination before administering the 13-valent pneumococcal conjugate vaccine (PCV 13). This was an open, prospective study on children and adolescents aged 5-18 years who had IBD and were naïve to pneumococcal vaccination. A single dose of PCV 13 was administered to each patient. The geometric mean concentrations (GMCs) were measured for all 13 serotypes. A total of 122 subjects completed the study. Prevaccination GMCs ranged from $0.55 \mu \mathrm{g} / \mathrm{ml}$ (serotype 4 ) to $4.26 \mu \mathrm{g} / \mathrm{ml}$ (serotype 19A). Prior to the administration of PCV 13, high GMCs were detected in older children and adolescents who had IBD and were naïve to pneumococcal vaccination.

Ke y words: autoimmune disease, Crohn's disease, PCV, ulcerative colitis, vaccine

Since 2013, the 13-valent pneumococcal conjugate vaccine (PCV 13) has been recommended in children and adolescents aged 6-17 years, regardless of whether they are healthy (Rubin etal., 2014) or suffer from immunocompromising conditions such as IBD (CDC, 2013). At the time of this study very little research has been conducted to determine the serological status of older children and adolescentswith respect to the $13 \mathrm{PCV}$ serotypes. Only two studies have been conducted to date: one in healthy young Americans (Frenck Jr. et al., 2014) and one in children and adolescents with perinatally acquired HIV infection in Africa (Bamford et al., 2014). Differences in preimmunization pneumococcal vaccine-specific serological status were observed between these studies. This could be explained by worldwide differences in pneumococcal serotype distribution modifying the natural response and by the impaired serological response of HIV-infected children. A recently published study assessed the prevaccination serological status of older Polish infants and toddlers who were naïve to pneumococcal vaccination (Wysocki et al., 2015). The aim of this report was to assess the pneumococcal serological status of older Polish children and adolescents with IBD prior to the administration of one dose of PCV 13.

This report was part of an open, prospective study that was conducted between April 2013 and March 2014 across six hospitals in Poland (cities of Warsaw, Poznan, Wroclaw, Katowice, Gdansk and Cracow) to compare the immunogenicity and safety of using PCV 13 in subjects with IBD versus healthy controls (grant of the Polish Ministry of Science and Higher

* Corresponding author: A. Banaszkiewicz, Department of Pediatric Gastroenterology and Nutrition, Medical University of Warsaw, Poland; e-mail: aleksandra.banaszkiewicz@gmail.com 
Education no. N404 077140 0771/B/P01/2011/40). Our part of the study focused on subjects between 5 and 18 years of age who had been diagnosed with IBD based on clinical signs and symptoms in addition to endoscopic, histologic and radiologic results, according to the Porto criteria (Levine et al., 2014). Additionally, the subjects had not been previously vaccinated with any of pneumococcal vaccines and had no history of IPD. IBD patients were included from any stage of the disease and treatment process. All participants received one dose of $0.5 \mathrm{ml} \mathrm{13-valent} \mathrm{PCV} \mathrm{(Diphtheria} \mathrm{CRM197}$ Protein) from Wyeth Pharmaceuticals, Inc. Blood samples were collected immediately prior to vaccination. Sera were stored at $-20^{\circ} \mathrm{C}$ to $-70^{\circ} \mathrm{C}$ until analysis was performed. Each serum sample was tested for serotype-specific anti-pneumococcal polysaccharide IgG antibodies to the 13 polysaccharides of $\operatorname{PCV} 13(1,3$, $4,5,6 \mathrm{~A}, 6 \mathrm{~B}, 7 \mathrm{~F}, 9 \mathrm{~V}, 14,18 \mathrm{C}, 19 \mathrm{~A}, 19 \mathrm{~F}$ and $23 \mathrm{~F}$ ) using a standardized enzyme linked immunoassay according to an adapted WHO protocol (WHO, 2005). To enhance the specificity of the serotype-specific antibodies, the assay included the preabsorption of test sera from the pneumococcal C polysaccharide and the pneumococcal polysaccharide from the non-vaccine 22F serotype (Wernette et al., 2003; Concepcion et al., 2001). All parents and children $\geq 16$ years old provided written informed consent. Geometric mean concentrations (GMCs) of prevaccination antibody levels were used as the measure of central tendency. Confidence intervals at $1-\alpha=0.05$ were computed (CI 95\%). This study was approved on Jan $26^{\text {th }} 2010$ by the Clinical Research Ethics Committee of the Medical University of Warsaw, Poland. This study was supported by grant no. N404 077140 0771/B/P01/2011/40 from the Polish Ministry of Science and Higher Education. The project was approved Febr. 4th, 2010.

This study included 122 older children and adolescents who had IBD (mean age 15.08 years, $60 \%$ boys). The prevaccination GMCs are presented in Table I.

In this report, we found high prevaccination GMCs for all 13 serotypes (range from $0.55 \mu \mathrm{g} / \mathrm{ml}$ for serotype 4 to 4.26 for serotype 19A). This is in accordance with previous studies conducted on healthy older children (Frenck Jr et al., 2014; Wysocki et al., 2015) and adolescents (Frenck Jr et al., 2014). These findings support the suggestion of natural exposure to vaccine serotypes. Notably, we observed high GMCs for both the most common $(1,14$ and 19F) and the most fatal $(3,4,19 \mathrm{~F}$, 14 and 19A) serotypes in Polish 5- to 25-year-old subjects with IPD (Skoczyńska et al., 2015). For children with chronic, potentially immunosuppressing conditions such as IBD, protection against a significant proportion of the serotypes that can cause IPD is extremely important. However, mass vaccination against pneumococcal disease has not yet been introduced in Poland.
Table I

Prevaccination geometric mean concentrations (GMCs) for 13 serotypes

\begin{tabular}{|c|c|}
\hline PCV 13 serotypes & Prevaccination GMC $(95 \%$ CI $)$ \\
\hline 1 & $0.83(0.71-0.98)$ \\
\hline 3 & $0.99(0.81-1.21)$ \\
\hline 4 & $0.55(0.46-0.65)$ \\
\hline 5 & $1.18(1.03-1.36)$ \\
\hline $6 \mathrm{~A}$ & $2.33(2-2.71)$ \\
\hline $6 \mathrm{~B}$ & $2.05(1.73-2.42)$ \\
\hline $7 \mathrm{~F}$ & $1.3(1.03-1.64)$ \\
\hline $9 \mathrm{~V}$ & $1.31(1.09-1.57)$ \\
\hline 14 & $3.86(3.08-4.84)$ \\
\hline $18 \mathrm{C}$ & $1.47(1.17-1.84)$ \\
\hline $19 \mathrm{~A}$ & $4.26(3.59-5.05)$ \\
\hline $19 \mathrm{~F}$ & $2.48(1.98-3.1)$ \\
\hline $23 \mathrm{~F}$ & $1.52(1.22-1.9)$ \\
\hline
\end{tabular}

We hope that the relatively high prevaccination GMCs that were observed will also offer protection against non-IPD; however, the concentration that would be required to confer protection against pneumococcal non-bacteremic pneumonia and pneumococcal otitis media remains unknown.

Our report has several advantages. Our work is only the second study to assess the use of PCV13 in older children and adolescents who are naïve to pneumococcal vaccines. Our study also provides data on the serological status of patients who were suffering from a chronic disease prior to the administration of PCV13 and adds evidence to the hypothesis that natural exposure to pneumococcal vaccine serotypes occurs in Poland: a country with very low PCV coverage and a lack of herd immunity. PCVs are still not part of the national vaccine program, and patients who elect to have vaccines are not reimbursed; thus, they are only available to a very small proportion of Polish children. Although our study group was small, it was still large enough to perform statistical analysis. A shortcoming of the present study is the lack of a functional response measurement for the serotypes.

High prevaccination pneumococcal GMCs of all PCV 13 serotypes were found in children and adolescents with IBD, suggesting that they previously acquired natural protection against IPD but not necessarily against non-IPD.

\section{Literature}

Bamford A., P. Kelleher, H. Lyall, M. Haston, M. Zancolli, D. Goldblatt and B. Kampmann. 2014. Serological response to 13 -valent pneumococcal conjugate vaccine in children and adolescents with perinatally acquired HIV infection. AIDS 28: 2033-2243. 
Centers for Disease Control and Prevention (CDC). 2013. Use of 13-valent pneumococcal conjugate vaccine and 23-valent pneumococcal polysaccharide vaccine among children aged $6-18$ years with immunocompromising conditions: recommendations of the Advisory Committee on Immunization Practices (ACIP). MMWR Morb. Mortal. Wkly. Rep. 62: 521-524.

Concepcion N.F. and C.E. Frasch. 2001. Pneumococcal type 22F polysaccharide absorption improves the specificity of a pneumococcal-polysaccharide enzyme-linked immunosorbent assay. Clin. Diagn. Lab. Immunol. 8: 266-272.

Frenck R.Jr., A. Thompson, S. Senders, L. Harris-Ford, M. Sperling, S. Patterson, C. Devlin, K.U. Jansen, W.C. Gruber, E.A. Emini and others. 2014. 13-Valent pneumococcal conjugate vaccine in older children and adolescents either previously immunized with or naïve to 7-valent pneumococcal conjugate vaccine. Pediatr. Infect. Dis. J. 33: 183-189.

Levine A., S. Koletzko, D. Turner, J.C. Escher, S. Cucchiara, L. de Ridder, K.L. Kolho, G. Veres, R.K. Russell, A. Paerregaard and others. 2014. ESPGHAN revised porto criteria for the diagnosis of inflammatory bowel disease in children and adolescents. J. Pediatr. Gastroenterol. Nutr. 58: 795-806.

Rubin L.G., M.J. Levin, P. Ljungman, E.G. Davies, R. Avery, M. Tomblyn, A. Bousvaros, S. Dhanireddy, L. Sung, H. Keyserling and others. 2014. Infectious diseases society of America. 2013 IDSA clinical practice guideline for vaccination of the immunocompromised host. Clin. Infect. Dis. 58:309-318.

Skoczyńska A., A. Kuch, E. Sadowy, I. Waśko, M. Markowska, P. Ronkiewicz, B. Matynia, A. Bojarska, K. Wasiak, A. Gołębiewska and others. 2015. Participants of a laboratory-based surveillance of community acquired invasive bacterial infections (BINet). Recent trends in epidemiology of invasive pneumococcal disease in Poland. Eur. J. Clin. Microbiol. Infect. Dis. 34: 779-787.

World Health Organisation (WHO). 2005. Pneumococcal conjugate vaccines. Recommendations for the production and control of pneumococcal conjugate vaccines. WHO Tech. Rep. Ser. 927 (Annex 2): 64-98. Wernette C.M., C.E. Frasch, D. Madore, G. Carlone, D. Goldblatt, B. Plikaytis, W. Benjamin, S.A. Quataert, S. Hildreth, D.J. Sikkema and others. 2003. Enzyme-linked immunosorbent assay for quantitation of human antibodies to pneumococcal polysaccharides. Clin. Diagn. Lab. Immunol. 10: 514-519.

Wysocki J., J. Brzostek, H. Szymański,B. Tetiurka, E. ToporowskaKowalska, K. Wasowska-Królikowska, D.A. Sarkozy, P.C. Giardina, W.C. Gruber and others. 2015. Immunogenicity and safety of a 13-valent pneumococcal conjugate vaccine administered to older infants and children naïve to pneumococcal vaccination. Vaccine 33: 1719-1725. 
